\title{
Article \\ Screen Time and Parents' Education Level Are Associated with Poor Adherence to the Mediterranean Diet in Spanish Children and Adolescents: The PASOS Study
}

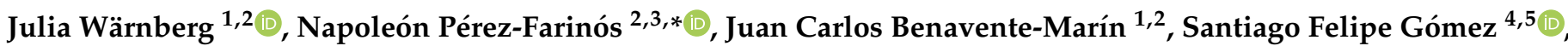

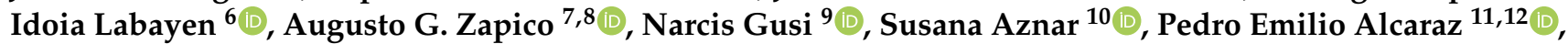 \\ Miguel González-Valeiro ${ }^{13}$ (D), Lluís Serra-Majem ${ }^{2,14}{ }^{(\mathbb{D}}$, Nicolás Terrados ${ }^{15}$, Josep A. Tur ${ }^{2,16}$ (D) Marta Segú ${ }^{17}$, \\ Camille Lassale $^{2,18}$ (D), Clara Homs ${ }^{4,19}$, Maddi Oses ${ }^{6}$ (D) Marcela González-Gross 2,7 (D), Jesús Sánchez-Gómez ${ }^{9}$, \\ Fabio Jiménez-Zazo ${ }^{10} \mathbb{D}$, Elena Marín-Cascales ${ }^{11} \mathbb{D}$, Marta Sevilla-Sánchez ${ }^{13} \mathbb{D}$, Estefanía Herrera-Ramos ${ }^{14} \mathbb{D}^{\mathbb{D}}$, \\ Susana Pulgar ${ }^{15}$, María del Mar Bibiloni ${ }^{2,16}$, Olga Sancho-Moron ${ }^{17}$, Helmut Schröder ${ }^{18,20}$ \\ and F. Javier Barón-López ${ }^{1,2}$ (D)
}

check for

updates

Citation: Wärnberg, J.; Pérez-Farinós N.; Benavente-Marín, J.C.; Gómez, S.F.; Labayen, I.; G. Zapico, A.; Gusi, N.; Aznar, S.; Alcaraz, P.E.; González-Valeiro, M.; et al. Screen Time and Parents' Education Level Are Associated with Poor Adherence to the Mediterranean Diet in Spanish Children and Adolescents: The PASOS Study. J. Clin. Med. 2021, 10, 795. https://doi.org/10.3390/ jcm10040795

Academic Editor: Jaakko Tuomilehto Received: 30 December 2020

Accepted: 7 February 2021

Published: 16 February 2021

Publisher's Note: MDPI stays neutral with regard to jurisdictional claims in published maps and institutional affiliations.

Copyright: (c) 2021 by the authors. Licensee MDPI, Basel, Switzerland. This article is an open access article distributed under the terms and conditions of the Creative Commons Attribution (CC BY) license (https:/ / creativecommons.org/licenses/by/ $4.0 /)$.
1 Epi-Phaan Research Group, School of Health Sciences, Universidad de Málaga, Instituto de Investigación Biomédica de Málaga (IBIMA), 29071 Málaga, Spain; jwarnberg@uma.es (J.W.); jc.benaventemarin@gmail.com (J.C.B.-M.); baron@uma.es (F.J.B.-L.)

2 Centro de Investigación Biomédica en Red Fisiopatología de la Obesidad y la Nutrición (CIBEROBN), Institute of Health Carlos III, 28029 Madrid, Spain; lluis.serra@ulpgc.es (L.S.-M.); pep.tur@uib.es (J.A.T.); classale@imim.es (C.L.); marcela.gonzalez.gross@upm.es (M.G.-G.); mar.bibiloni@uib.es (M.d.M.B.)

3 Epi-Phaan Research Group, School of Medicine, Universidad de Málaga, Instituto de Investigación Biomédica de Málaga (IBIMA), 29071 Málaga, Spain

4 Programs, Gasol Foundation, Sant Boi de Llobregat, 08830 Barcelona, Spain; sgomez@gasolfoundation.org (S.F.G.); choms@gasolfoundation.org (C.H.)

5 GREpS, Health Education Research Group, Nursing and Physiotherapy Department, University of Lleida, 25198 Lleida, Spain

6 ELIKOS Group, Institute for Innovation and Sustainable Development in Food Chain (IS-FOOD), Instituto de Investigación Sanitaria de Navarra, Public University of Navarre, 31006 Pamplona, Spain; idoia.labayen@unavarra.es (I.L.); maddi.oses@unavarra.es (M.O.)

7 ImFINE Research Group, Department of Health and Human Performance, Universidad Politecnica de Madrid, 28040 Madrid, Spain; azapico@edu.ucm.es

8 Department of Didactics of Language, Arts and Physical Education, Universidad Complutense de Madrid, 28040 Madrid, Spain

9 Physical Activity and Quality of Life Research Group (AFYCAV), Faculty of Sport Sciences, University of Extremadura, 10003 Caceres, Spain; narcis.gusi@gmail.com (N.G.); jesanchezg@unex.es (J.S.-G.)

10 PAFS Research Group, Faculty of Sports Sciences, University of Castilla-La Mancha-Toledo Campus, 45071 Toledo, Spain; Susana.Aznar@uclm.es (S.A.); Fabio.jimenez@uclm.es (F.J.-Z.)

11 Research Center for High Performance Sport, San Antonio Catholic University of Murcia, 30830 Murcia, Spain; palcaraz@ucam.edu (P.E.A.); emarin@ucam.edu (E.M.-C.)

12 Faculty of Sport Sciences, San Antonio Catholic University of Murcia, 30107 Murcia, Spain

13 Faculty of Sports Sciences and Physical Education, Universidade da Coruña, 15179 A Coruña, Spain; miguel.gonzalez.valeiro@udc.es (M.G.-V.); marta.sevilla@udc.es (M.S.-S.)

14 Research Institute of Biomedical and Health Sciences (IUIBS), University of Las Palmas de Gran Canaria, 35016 Las Palmas, Spain; faniya1@gmail.com

15 Regional Unit of Sports Medicine-Municipal Sports Foundation of Avilés and Health Research Institute of the Principality of Asturias (ISPA), 33401 Avilés, Spain; nterrados@aviles.es (N.T.); susanapulgarmunoz@gmail.com (S.P.)

16 Research Group of Community Nutrition and Oxidative Stress, University of the Balearic Islands and IDISBA, 07122 Palma de Mallorca, Spain

17 Probitas Foundation, 08022 Barcelona, Spain; marta.segu@fundacionprobitas.org (M.S.); olga.sancho@grifols.com (O.S.-M.)

18 Cardiovascular Risk and Nutrition Research Group, Hospital del Mar Institute for Medical Research (IMIM), 08003 Barcelona, Spain; HSchoeder@imim.es

19 Global Research on Wellbeing (GRoW), Blanquerna Ramon Llull University Faculty of Health Sciences, 08025 Barcelona, Spain

20 Centro de Investigación Biomédica en Red Fisiopatología de Epidemiología y Salud Pública (CIBERESP), Institute of Health Carlos III, 28029 Madrid, Spain

* Correspondence: napoleon.perez@uma.es; Tel.: +34-951-952-840 


\begin{abstract}
The aim of this study is to evaluate if screen time and parents' education levels are associated with adherence to a Mediterranean dietary pattern. This cross-sectional study analyzed a representative sample of 3333 children and adolescents (8 to 16 years) included in the Physical Activity, Sedentarism, lifestyles and Obesity in Spanish youth (PASOS) study in Spain (which ran from March 2019 to February 2020). Data on screen time (television, computer, video games, and mobile phone) per day, Mediterranean diet adherence, daily moderate or vigorous physical activity, and parents' education levels were gathered using questionnaires. A descriptive study of the variables according to sex and parents' education level was performed. Logistic regression models (adjusted by sex and weight status) were fitted to evaluate the independent association between screen time and Kids' level of adherence to the Mediterranean diet (KIDMED) index, as well as some of its items. A greater amount of screen time was associated with worse adherence to the Mediterranean diet; a lower consumption of fruit, vegetables, fish, legumes, and nuts; and a greater consumption of fast food, sweets, and candies. A lower parents' education level was associated with worse adherence to the Mediterranean diet. It is necessary to promote the responsible, limited use of screen time, especially in children with parents with a lower education level.
\end{abstract}

Keywords: screen time; education level; eating pattern; Mediterranean diet

\title{
1. Introduction
}

Childhood obesity is a significant public health problem worldwide [1,2]. In addition to its short-term health consequences, it is related to obesity in adulthood and thus to numerous other diseases that cause a high level of mortality, morbidity, and disability [3,4]. Obesity is highly prevalent in children and adolescents, especially in certain countries or regions, including southern Europe and Spain [5-7]. Childhood obesity is related to an imbalance between energy intake and expenditure, which leads to an increase in weight. This increase in weight has been associated with different lifestyle factors, such as diet, sedentary behavior, and physical activity [8-10]. Among dietary patterns, the Mediterranean diet is defined as an eating pattern that includes the intake of a large amount of fruit, vegetables, legumes, grains, nuts, and olive oil; moderate consumption of fish, dairy products, and eggs; and reduced consumption of meat. The Mediterranean diet has been demonstrated to be a dietary pattern that has favorable effects on health, not just in terms of weight control, but also in the prevention of non-communicable diseases [11,12]. Therefore, it is an ideal dietary pattern during childhood and adolescence. Ceasing to follow this dietary pattern could lead to health deficiencies in children and adolescents [13] and, as such, it is important to know the level of adherence to the Mediterranean diet and factors that influence it.

In addition to diet, other factors have been studied as determinants of childhood obesity. Among them are those related to physical activity and sedentarism. Various studies, such as those by Bawaked et al. and Arriscado et al., have documented that low levels of physical activity are associated with a lower degree of adherence to the Mediterranean diet among children between 8 and 12 years of age [14,15]. In addition to low levels of activity, a greater amount of time spent on sedentary activities seems to be related to lower adherence to the Mediterranean diet. Among these sedentary activities, screen time is being studied as a factor associated with unhealthy dietary patterns. The mechanisms by which screen time is associated with childhood and adolescent obesity are not entirely clear. Apart from the substitution of physical activity with sedentary entertainment [16,17], it has been suggested that increased energy intake may be associated with watching television or playing video games through a reduction in the sensation of satiety and the fostering of unhealthy eating habits [18]. Other factors have also been considered, such as children's exposure to advertising for food and beverages that are high in saturated fats, sugars, or salt, which could promote their desire to consume these products. Likewise, screen time is interrelated with insufficient sleep time in children 
which, through endocrine mechanisms, could favor childhood and adolescent obesity by means of its effects on eating patterns $[19,20]$. Indeed, the amount of time per day that children and adolescents spend on passive screen time entertainment such as television, mobile telephones, computers, and video games, as well as having a television in their room, seem to play a role [21-23]. A recent study by Tapia Serrano et al. found that a greater amount of screen time was associated with worse adherence to the Mediterranean diet in adolescents (12 to 14 years of age) in Extremadura (western Spain) [13].

In addition to the aforementioned factors, parents' education level also appears to be associated with factors that may influence childhood and adolescent obesity, such as dietary and physical activity habits [24,25]. For years, education level has been considered to be one of the strongest predictors of health and mortality, even more so than income level [26]. Therefore, we believe it is relevant to evaluate parents' education level as a determining factor in dietary habits and, in this case, in adherence to the Mediterranean diet in children and adolescents.

Studies have been conducted in Spain which evaluate the association between screen time and Mediterranean diet and dietary patterns, but the sample sizes have been small, the age groups have been narrow, or they have only focused on certain regions [13-15,27,28]. A study such as this one, with a large sample size that is representative of Spain's child and adolescent population, is necessary.

The aims of this study are first to evaluate if screen time is associated with the Mediterranean dietary pattern in children and adolescents after adjusting for other variables, and second to determine adherence to the Mediterranean diet according to parents' education level.

\section{Materials and Methods}

\subsection{Design, Setting, and Participants}

This work is a cross-sectional study based on the Physical Activity, Sedentarism, lifestyles and Obesity in Spanish youth (PASOS) study. A complete description of the design and methodology of the PASOS study has previously been published [29]. The PASOS study is a multicenter, cross-sectional, population-based study conducted in a representative sample of the Spanish population aged 8 to 16 years. Its objective is to determine levels of physical activity, sedentarism, lifestyle factors, and weight status.

Randomization of the participating schools was performed by means of a multistage sampling procedure, as previously described. Data were collected between March 2019 and February 2020 in 244 primary and secondary schools across all 17 Spanish regions. Informed consent was obtained from 4092 parents or guardians some weeks before the data collection day. A parental questionnaire was also sent home in paper format to be self-reported and sent back to school. On one occasion during school hours, trained researchers visited the participating school for data collection of children and adolescents. Anthropometric measurements of children and adolescents were taken by trained personnel. Questionnaires were self-reported by the children and adolescents online at school in the presence of trained personnel who were available to answer any possible questions.

From 4092 children and adolescents whose parents signed the consent, 326 were excluded because they were under 8 or over 16 years old, 216 were excluded because they did not attend school the day the data collection took place, and 217 children and adolescents were excluded because their parents or guardians did not return the questionnaire with information about their level of education. This analysis included 3333 children and adolescents aged between 8 and 16.99 years who had complete information on all variables of interest. These included being present at school on the day data were collected and having anthropometric measurements taken; having valid data from the Kids' level of adherence to the Mediterranean diet (KIDMED), screen time use, and Physical Activity Physical Activity Unit 7 item Screener (PAU-7S) questionnaires; and having the parental questionnaire responded to by at least one parent or guardian. 


\subsection{Study Variables}

\subsubsection{Outcome Variables}

The outcome variables were those related to the adherence to the Mediterranean diet of children and adolescents. The KIDMED index evaluates the habitual diet and degree of adherence to the Mediterranean diet. It was developed and has been validated in Spanish children and adolescents $[12,30,31]$.

The questionnaire includes 16 yes-or-no questions: 4 questions that denote low adherence and have a score of -1 , and 12 questions that denote high adherence and have a score of +1 . Therefore, the KIDMED index score ranges from -4 to +12 points. The KIDMED index was also used to classify participants into three categories: low adherence ( 3 or fewer points), medium adherence (4-7 points), and high adherence ( 8 or more points) [31]. For multivariate models (binary logistic regression), the KIDMED index was coded into two categories: high adherence and medium or low adherence.

Twelve of the 16 questionnaire items corresponding to frequency of intake of specific food groups were evaluated and are presented individually: one serving of fruit per day, more than one serving of fruit per day, one serving of fresh or cooked vegetables per day, more than one serving of fresh or cooked vegetables per day, at least 2-3 servings of fish per week, at least one serving of legumes per week, at least 5 servings of pasta or rice per week, at least one serving of dairy products (yogurt, milk) per day, at least 2-3 servings of nuts or seeds per week, the use of olive oil at home, sweets or candy several times per day and eating at a fast food restaurant one or more times per week.

\subsubsection{Exposure Variable}

The exposure variables were mean daily screen time measured in hours and parents' education level. In the PASOS study, screen time was evaluated using the Healthy Lifestyle in Europe by Nutrition in Adolescence (HELENA) (study's screen time-based sedentary behavior questionnaire [32], which asks about the time spent per day on four activities: watching television, playing on the computer, playing video games, and using a mobile telephone. It enquires about weekdays and weekends separately. To calculate mean daily time, the weighted mean was calculated for weekdays ( 5 days) and weekends ( 2 days).

Parents' education level was classified into three categories: "no formal or only primary school education", "secondary school", or "university". When the parents had different education levels, the highest one was chosen. Children and adolescents were then classified into one of three categories according to the parents' education level.

\subsubsection{Covariates}

The sex and age of children and adolescents were reported by parents on the informed consent form. In addition, the following covariates were selected from among those that were collected in the PASOS study: participants' weight status and mean daily and weekly time spent doing moderate or vigorous physical activity (MVPA). These covariates were chosen because as they are related to the dependent variable and exposure variables, it is believed they may have a confounding effect on the estimations $[10,13,33]$.

Children and adolescents' weight status was assessed using body mass index (BMI), calculated using the formula: weight $(\mathrm{kg}) / \mathrm{height}^{2}\left(\mathrm{~m}^{2}\right)$. Weight and height were measured according to the World Health Organization (WHO) standardized protocol [34]. Body weight was measured to the nearest $100 \mathrm{~g}$ using an electronic scale (SECA 899, SECA $\mathrm{GmbH}$, Hamburg, Germany), and height was measured to the nearest $1 \mathrm{~mm}$ with a portable stadiometer (SECA 217, SECA GmbH, Hamburg, Germany). The weight status variable was classified into two categories: normal weight and excess weight, which included overweight and obesity. The BMI-for-age cut-off points of the WHO child growth standards were used to define overweight and obesity [35].

The self-administered PAU-7S questionnaire, which consists of seven questions on physical activity, was used to estimate mean time spent daily (in minutes) and weekly (in hours) doing MVPA [29]. The PAU-7S questionnaire has been validated in a randomized 
sample of 321 participants from the PASOS study that completed the PAU-7S twice and wore an accelerometer (reference method) for at least 7 consecutive days. It showed a good internal consistency (Cronbach's alpha: 0.76), a fair correlation with data measured with an accelerometer (Spearman's correlation coefficient: 0.62), and a fair concordance (kappa value: 0.24 ) (unpublished data).

\subsection{Statistical Analysis}

A descriptive study of the variables was conducted, calculating the mean and standard deviation for quantitative variables (age, daily screen time, MVPA/week, MVPA/day, and KIDMED index score) and absolute frequency and percentage for qualitative variables (age group, sex, categories of KIDMED index, and KIDMED questionnaire items). This descriptive study was conducted on the total sample according to parents' education level group and according to participants' sex. Differences among the groups were evaluated using the chi-square test for qualitative variables (with Bonferroni-corrected $p$-values for pairwise comparisons) and the ANOVA test for quantitative variables (with Bonferroni corrections for multiple testing). Likewise, a descriptive analysis of the quantitative variables was performed separately for children and adolescents.

To assess the independent association between screen time and adherence to the Mediterranean diet, various multivariate models of binary logistic regressions were adjusted. In the first, the dependent variable was adherence to the Mediterranean diet as measured by the KIDMED index (high adherence and medium or low adherence) and the independent variables were mean daily screen time (hours) and parents' education level. The model was adjusted by sex and weight status and was conducted separately in children and adolescents. In addition, other models were fitted, one for each KIDMED index item as the dependent variable and screen time as the independent variable, adjusted for sex, parents' education level, weight status, and MVPA.

\subsection{Ethical Aspects}

The PASOS study was approved by the Ethics Committee of the Fundació Sant Joan de Déu, Barcelona, Spain. A signed informed consent form was obtained from the parents or legal guardians of each participant. The study was performed according to the guidelines of the Declaration of Helsinki.

\section{Results}

A description of the total sample and of participants according to parents' education level can be seen in Tables 1 and 2. A total of 1500 participants (45.0\%) were between 8 and 11 years of age (children,) and $1833(55.0 \%)$ were between 12 and 16 years of age (adolescents). Of the total sample, $52.1 \%$ were girls and $47.9 \%$ were boys. No differences were observed in parents' education level according to participants' sex.

Mediterranean diet adherence was low in $10.2 \%$, medium in $49.3 \%$, and high in $40.5 \%$ of the total population. Adherence was high in $49.6 \%$ of children whose parents had a university education, in $36.3 \%$ of children whose parents had a secondary school education, and in $31.3 \%$ of children whose parents had a primary school or no formal education. These differences were statistically significant. A significantly higher percentage of children whose parents had a university education consumed fruit, vegetables, and dairy products daily, and fish, legumes, and nuts weekly. A significantly higher percentage of children whose parents had secondary or primary/no formal education consumed more fast food and sweets and candy (Table 1).

The mean KIDMED index score was significantly higher in children and adolescents whose parents had a university education than children whose parents had either secondary or primary/no formal education (Table 2). 


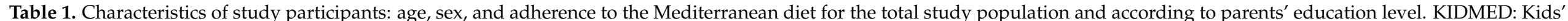
level of adherence to the Mediterranean diet.

\begin{tabular}{|c|c|c|c|c|c|c|c|c|c|}
\hline \multirow[t]{2}{*}{ Variables } & \multicolumn{2}{|c|}{ Total } & \multicolumn{2}{|c|}{$\begin{array}{c}\text { Primary School or No } \\
\text { School }\end{array}$} & \multicolumn{2}{|c|}{ Secondary School } & \multicolumn{2}{|c|}{ University } & \multirow[b]{2}{*}{$p$} \\
\hline & $n$ & $\%$ & $n$ & $\%$ & $n$ & $\%$ & $n$ & $\%$ & \\
\hline \multicolumn{10}{|l|}{ Age } \\
\hline Children, 8-11 years & 1500 & 45.0 & 165 & 11.0 & 764 & 50.9 & 571 & 38.1 & \\
\hline Adolescents, $12-16$ years & 1833 & 55.0 & 203 & 11.1 & 1014 & 55.3 & 616 & 33.6 & \\
\hline \multicolumn{10}{|l|}{ Sex } \\
\hline Boys & 1595 & 47.9 & 189 & 11.8 & 833 & 52.2 & 573 & 35.9 & \\
\hline Girls & 1738 & 52.1 & 179 & 10.3 & 945 & 54.4 & 614 & 35.3 & 0.271 \\
\hline Low & 339 & 10.2 & 42 & $11.4^{\mathrm{a}}$ & 226 & $12.7^{\mathrm{a}}$ & 71 & $6.0^{\mathrm{b}}$ & \\
\hline Medium & 1644 & 49.3 & 211 & $57.3^{\mathrm{a}}$ & 906 & $51.0^{\mathrm{b}}$ & 527 & $44.4^{\mathrm{c}}$ & \\
\hline High & 1350 & 40.5 & 115 & $31.3^{\mathrm{a}}$ & 646 & $36.3^{\mathrm{a}}$ & 589 & $49.6^{\mathrm{b}}$ & $<0.001$ \\
\hline \multicolumn{10}{|l|}{ Daily fruit consumption } \\
\hline No & 926 & 27.8 & 103 & $28.0^{\mathrm{a}}$ & 548 & $30.8^{\mathrm{a}}$ & 275 & $23.2^{b}$ & \\
\hline Yes & 2407 & 72.2 & 265 & $72.0^{\mathrm{a}}$ & 1230 & $69.2^{\mathrm{a}}$ & 912 & $76.8^{b}$ & $<0.001$ \\
\hline \multicolumn{10}{|c|}{ Daily consumption of more than one serving of fruit } \\
\hline No & 1640 & 49.2 & 181 & $49.2^{\mathrm{a}}$ & 963 & $54.2^{\mathrm{a}}$ & 496 & $41.8^{\mathrm{b}}$ & \\
\hline No & 1198 & 35.9 & 148 & $40.2^{\mathrm{a}}$ & 684 & $38.5^{\mathrm{a}}$ & 366 & $30.8^{\mathrm{b}}$ & \\
\hline Yes & 2135 & 64.1 & 220 & $59.8^{\mathrm{a}}$ & 1094 & $61.5^{\mathrm{a}}$ & 821 & $69.2^{b}$ & $<0.001$ \\
\hline \multicolumn{10}{|c|}{ Daily consumption of more than one serving of vegetables } \\
\hline No & 2260 & 67.8 & 253 & $68.8^{\mathrm{a}}$ & 1229 & $69.1^{\mathrm{a}}$ & 778 & $65.5^{\mathrm{a}}$ & \\
\hline Yes & 1073 & 32.2 & 115 & $31.3^{\mathrm{a}}$ & 549 & $30.9^{a}$ & 409 & $34.5^{\mathrm{a}}$ & 0.114 \\
\hline \multicolumn{10}{|c|}{ Fish consumption at least $2-3$ times per week } \\
\hline No & 1260 & 37.8 & 152 & $41.3^{\mathrm{a}}$ & 741 & $41.7^{\mathrm{a}}$ & 367 & $30.9^{b}$ & \\
\hline Yes & 2073 & 62.2 & 216 & $58.7^{\mathrm{a}}$ & 1037 & $58.3^{\mathrm{a}}$ & 820 & $69.1^{b}$ & $<0.001$ \\
\hline \multicolumn{10}{|c|}{ Legume consumption at least once per week } \\
\hline No & 1018 & 30.5 & 129 & $35.1^{\mathrm{a}}$ & 561 & $31.6^{\mathrm{a}, \mathrm{b}}$ & 328 & $27.6^{\mathrm{b}}$ & \\
\hline Yes & 2315 & 69.5 & 239 & $64.9^{a}$ & 1217 & $68.4^{\mathrm{a}, \mathrm{b}}$ & 859 & $72.4^{b}$ & 0.010 \\
\hline
\end{tabular}


Table 1. Cont.

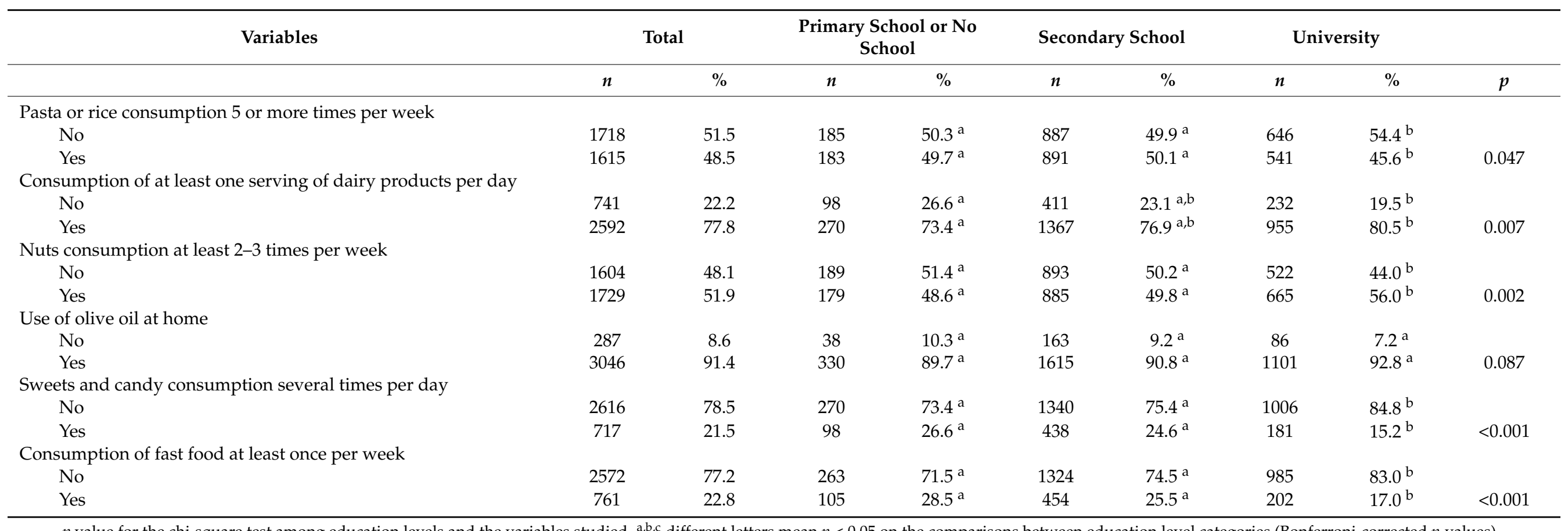

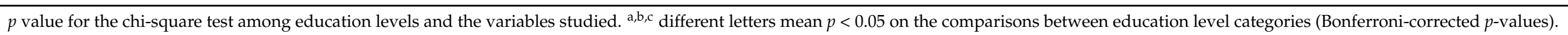


Table 2. Characteristics of study participants: age, screen time, physical activity, and KIDMED index for the total study population and according to parents' education level.

\begin{tabular}{|c|c|c|c|c|c|c|c|c|c|c|c|c|c|c|c|c|}
\hline \multirow[b]{3}{*}{ Variables } & \multicolumn{2}{|c|}{ Total } & \multicolumn{6}{|c|}{ Children (8-11 Years) } & & \multicolumn{7}{|c|}{ Adolescents (12-16 Years) } \\
\hline & \multirow[b]{2}{*}{ Mean } & \multirow[b]{2}{*}{ SD } & \multicolumn{2}{|c|}{$\begin{array}{c}\text { Primary School or } \\
\text { No School }\end{array}$} & \multicolumn{2}{|c|}{$\begin{array}{l}\text { Secondary } \\
\text { School }\end{array}$} & \multicolumn{2}{|c|}{ University } & & \multicolumn{2}{|c|}{$\begin{array}{c}\text { Primary School or } \\
\text { No School }\end{array}$} & \multicolumn{2}{|c|}{$\begin{array}{l}\text { Secondary } \\
\text { School }\end{array}$} & \multicolumn{2}{|c|}{ University } & \\
\hline & & & Mean & SD & Mean & SD & Mean & SD & & Mean & SD & Mean & SD & Mean & SD & \\
\hline Age (years) & 12.5 & 2.3 & $10.3^{\mathrm{a}}$ & 1.0 & $10.4^{\mathrm{a}}$ & 1.0 & $10.4^{\mathrm{a}}$ & 1.0 & & $14.3^{\mathrm{a}}$ & 1.3 & $14.4^{\mathrm{a}}$ & 1.4 & $14.2^{\mathrm{a}}$ & 1.3 & \\
\hline Daily screen time (minutes) & 207.9 & 143.2 & $173.3^{\mathrm{a}}$ & 131.9 & $170.9^{\mathrm{a}}$ & 139.9 & $125.0^{\mathrm{b}}$ & 112.2 & * & $266.2^{a}$ & 143.7 & $267.7^{\mathrm{a}}$ & 139.2 & $222.2^{b}$ & 127.3 & * \\
\hline MVPA/week (minutes) & 870.0 & 540.3 & $914^{\mathrm{a}}$ & 498.5 & $938.7^{\mathrm{a}}$ & 512.9 & $1004.0^{b}$ & 512.2 & * & $764.2^{\mathrm{a}}$ & 531.5 & $765.3^{a}$ & 547.8 & $855.7^{\mathrm{b}}$ & 560.0 & * \\
\hline MVPA/day (minutes) & 124.3 & 77.2 & $130.6^{\mathrm{a}}$ & 71.2 & $134.1^{\mathrm{a}}$ & 73.3 & $143.4^{b}$ & 73.2 & * & $109.2^{\mathrm{a}}$ & 75.9 & $109.3^{a}$ & 78.3 & $122.2^{b}$ & 80.0 & * \\
\hline
\end{tabular}

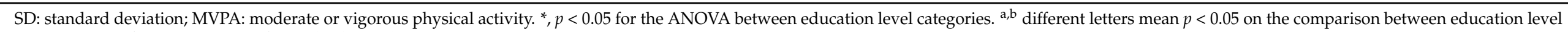
categories (Bonferroni correction for multiple tests). 
Mean daily screen time was $206.5 \mathrm{~min}$ in the total sample (Table 2). Among children aged 8 to 11 years, mean daily screen time was significantly lower in children whose parents had a university education level than in children whose parents had a secondary or primary/no formal education. Among adolescents, mean daily screen time was also significantly lower in children whose parents had a university education level than in those whose parents had a secondary or primary/no formal education.

MVPA time per day was also significantly higher in children and adolescents whose parents had a university education level with respect to those whose parents had secondary or primary/no formal education (Table 2). There were no differences between children and adolescents whose parents had secondary education and those whose parents had primary/no formal education.

There were no differences according to sex on the KIDMED index, but there were differences in screen time and physical activity (Table 3). In both children and adolescents, mean daily screen time was significantly higher among boys than girls. MVPA time per day was also significantly higher for boys than girls, both among children and adolescents.

Table 3. Characteristics of study participants: age, screen time, physical activity, and KIDMED index for the total study population and according to sex.

\begin{tabular}{|c|c|c|c|c|c|c|c|c|c|c|c|c|}
\hline \multirow[b]{3}{*}{ Variables } & \multicolumn{2}{|c|}{ Total } & \multicolumn{4}{|c|}{ Children (8-11 Years) } & & \multicolumn{5}{|c|}{ Adolescents (12-16 Years) } \\
\hline & \multirow[b]{2}{*}{ Mean } & \multirow[b]{2}{*}{ SD } & \multicolumn{2}{|c|}{ Boys } & \multicolumn{2}{|c|}{ Girls } & & \multicolumn{2}{|c|}{ Boys } & \multicolumn{2}{|c|}{ Girls } & \\
\hline & & & Mean & SD & Mean & SD & & Mean & SD & Mean & SD & \\
\hline Age (years) & 12.5 & 2.3 & 10.4 & 1.0 & 10.4 & 1.0 & & 14.3 & 1.3 & 14.3 & 1.3 & \\
\hline Daily screen time (minutes) & 207.9 & 143.2 & 184.0 & 144.8 & 124.5 & 108.6 & * & 271.6 & 144.7 & 235.1 & 128.3 & * \\
\hline MVPA/week (minutes) & 870.0 & 540.3 & 1037.9 & 518.3 & 886.6 & 494.7 & * & 929.9 & 554.9 & 677.1 & 520.8 & * \\
\hline MVPA/day (minutes) & 124.3 & 77.2 & 148.3 & 74.0 & 126.7 & 70.7 & * & 132.8 & 79.3 & 96.7 & 74.4 & * \\
\hline KIDMED index & 6.8 & 2.5 & 7.0 & 2.5 & 7.1 & 2.5 & & 6.7 & 2.4 & 6.4 & 2.5 & * \\
\hline
\end{tabular}

${ }^{*}, p<0.05$ for the difference of means between sexes.

The adjusted odds ratio (OR) and 95\% confidence intervals (CI) of the multivariate analysis can be seen in Tables 4 and 5 . An additional hour of screen time was significantly associated with a greater probability of medium or low adherence to the Mediterranean diet, as measured by the KIDMED index, both in children (OR: 1.18; 95\% CI: 1.11-1.24) and adolescents (OR: 1.23; 95\% CI: 1.17-1.27). Low education levels were also significantly associated with worse adherence to the Mediterranean diet in children and adolescents (Table 4). On the other hand, one additional hour of screen time in children was significantly associated with a lower probability of daily fruit and vegetable consumption, daily consumption of more than one serving of fruit, and legume consumption more than once per week and with a greater probability of fast food consumption one or more times per week and the consumption of sweets or candy several times per day. Among adolescents, similar statistically significant associations were also found, except for the daily consumption of more than one serving of vegetables (Table 5).

Table 4. Adjusted odds ratio (OR) and 95\% confidence interval (CI) for the effects of screen time and parents' education level on low or medium Mediterranean diet adherence (KIDMED index $<8$ ).

\begin{tabular}{|c|c|c|c|c|c|c|c|c|}
\hline \multirow{3}{*}{$\begin{array}{l}\text { Variables } \\
\text { Daily screen time (hours) }\end{array}$} & \multicolumn{4}{|c|}{ Children (8-11 Years) } & \multicolumn{4}{|c|}{ Adolescents (12-16 Years) } \\
\hline & \multirow{2}{*}{$\frac{\text { OR }}{1.178}$} & \multicolumn{2}{|c|}{$95 \%$ CI } & \multirow{2}{*}{$\begin{array}{c}\frac{p}{<0.001} \\
<\end{array}$} & \multirow{2}{*}{$\frac{\text { OR }}{1.225}$} & \multicolumn{2}{|c|}{$95 \% \mathrm{CI}$} & \multirow{2}{*}{$\begin{array}{c}p \\
<0.001\end{array}$} \\
\hline & & 1.116 & 1.243 & & & 1.167 & 1.286 & \\
\hline Education level & & & & & & & & \\
\hline University & 1 & & & & 1 & & & \\
\hline Secondary school & 1.378 & 1.102 & 1.724 & 0.005 & 1.641 & 1.327 & 2.029 & $<0.001$ \\
\hline Primary school or no school & 1.117 & 0.902 & 1.383 & 0.003 & 2.192 & 1.531 & 3.138 & $<0.001$ \\
\hline
\end{tabular}


Table 5. Adjusted OR and 95\% CI for the effects of screen time on dietary habits selected from the KIDMED index.

\begin{tabular}{|c|c|c|c|c|c|c|c|c|}
\hline \multirow{3}{*}{$\begin{array}{l}\text { Variables } \\
\text { Daily fruit consumption }\end{array}$} & \multicolumn{4}{|c|}{ Children (8-11 Years) } & \multicolumn{4}{|c|}{ Adolescents (12-16 Years) } \\
\hline & \multirow{2}{*}{$\begin{array}{c}\text { OR } \\
0.925\end{array}$} & \multicolumn{2}{|c|}{$95 \% \mathrm{CI}$} & \multirow{2}{*}{$\frac{p}{0.006}$} & \multirow{2}{*}{$\frac{\text { OR }}{0.895}$} & \multicolumn{2}{|c|}{$95 \% \mathrm{CI}$} & \multirow{2}{*}{$\frac{p}{<0.001}$} \\
\hline & & 0.875 & 0.978 & & & 0.856 & 0.936 & \\
\hline Daily consumption of more than one serving of fruit & 0.886 & 0.843 & 0.933 & $<0.001$ & 0.901 & 0.862 & 0.942 & $<0.001$ \\
\hline Daily vegetable consumption & 0.915 & 0.870 & 0.962 & $<0.001$ & 0.914 & 0.876 & 0.955 & $<0.001$ \\
\hline $\begin{array}{l}\text { Daily consumption of more than one serving of } \\
\text { vegetables }\end{array}$ & 0.929 & 0.880 & 0.980 & 0.007 & 0.988 & 0.943 & 1.035 & 0.609 \\
\hline Fish consumption at least 2-3 times per week & 0.903 & 0.858 & 0.949 & $<0.001$ & 0.915 & 0.877 & 0.955 & $<0.001$ \\
\hline Legume consumption more than once per week & 0.898 & 0.853 & 0.944 & $<0.001$ & 0.920 & 0.880 & 0.962 & $<0.001$ \\
\hline Pasta or rice consumption 5 or more times per week & 1.055 & 1.004 & 1.108 & 0.032 & 1.054 & 1.011 & 1.099 & 0.013 \\
\hline $\begin{array}{l}\text { Consumption of at least one serving of dairy products } \\
\text { per day }\end{array}$ & 1.025 & 0.969 & 1.084 & 0.397 & 1.014 & 0.962 & 1.068 & 0.614 \\
\hline Nuts consumption at least 2-3 times per week & 0.941 & 0.896 & 0.989 & 0.016 & 0.966 & 0.926 & 1.007 & 0.106 \\
\hline Use of olive oil at home & 1.003 & 0.934 & 1.077 & 0.936 & 1.057 & 0.961 & 1.164 & 0.255 \\
\hline Sweets and candy consumption several times per day & 1.206 & 1.140 & 1.276 & $<0.001$ & 1.256 & 1.196 & 1.319 & $<0.001$ \\
\hline Consumption of fast food at least once per week & 1.168 & 1.106 & 1.234 & $<0.001$ & 1.192 & 1.137 & 1.249 & $<0.001$ \\
\hline
\end{tabular}

Adjusted for sex, parents' education level, weight status, and MVPA.

\section{Discussion}

Numerous studies have examined the relationship between time spent on passive entertainment such as television, mobile telephones, or video games and the presence of or predisposition to childhood and adolescent obesity [36-45]. However, few studies have been conducted on screen time and its association with eating patterns [46-48]. This study found evidence that in children and adolescents of both sexes, an increase in screen time is associated with a low adherence to the Mediterranean diet; greater consumption of fast food, sweets, and candy; and lower consumption of fruit, vegetables, legumes, dairy products, fish, and nuts. This association is consistent with what is reported in the scientific literature $[37,49,50]$. Estimated screen time is greater among adolescents than children, which is also in line with what has been noted in other studies [25,51].

One possible explanation for these results could be that consumption of products rich in saturated fats, salt, or sugar is higher among children and adolescents who spend more time in front of screens because they pay less attention to what they eat while they are doing another activity $[40,46]$. In addition, many of the advertisements on television or the internet, especially during programs aimed at children or young people, are for food and beverages that have high energy, salt, fat, or sugar content [52-54].

In this study, a consistent association has been observed between screen time and fruit and vegetable consumption such that the greater the amount of screen time, the lower the probability of daily fruit or vegetable consumption or daily consumption of more than one serving of fruit. These results are highly relevant because very few studies have documented this association. López-Gil et al. observed a similar relationship for children, but their findings were only among girls, in a non-representative and smaller sample size than ours, and in a Spanish region that produces a lot of fruit and vegetables [55].

The decrease in daily fruit and vegetable consumption associated with a greater amount of screen time may be related to a substitution effect; fruit and vegetables may be in competition with different groups of products with a high energy content, which encompasses a very wide range of products [56]. This occurs despite the fact that high exposure to advertisements and campaigns for fruit and vegetables is associated with a greater consumption of these products [57].

Our study also noted an association between screen time and a greater consumption of food in fast food establishments, as well as of sweets and candy. Similar observations were noted in recent studies by Benaich et al. [58] and Vizcaino et al. [59].

Among the results obtained, it was found that screen time is significantly higher among boys than girls, both in children and adolescents. These differences were also 
reported in a recent study by Myszkowska-Ryciak et al. [60]. This finding must be taken into consideration when it comes to planning targeted and general prevention strategies.

It is important to note that the results of our research show an association between screen time and a low adherence to the Mediterranean diet that differ according to parents ${ }^{\prime}$ education level such that the lower the education level, the greater the screen time. A work by Abdel Magid et al. showed that among adolescents in the United States of America, screen time was higher in those whose parents had a low level of education [61]. Our results are also in line with a study by Pons et al. which indicated that a high education level among mothers is associated with lesser screen time and other healthy habits $[14,25]$. The mechanism which underlies the association between a lower educational level and a greater amount of screen time is not entirely clear. However, some theoretical models have been proposed. Various studies maintain that this association can be explained by the impact of education on healthy lifestyles, more so than better access to resources $[62,63]$. The SLOTH model, developed by Cawley in 2004, considers the allocation of time to various activities. This model assumes that individuals choose how to spend their time according to utility and cost $[64,65]$. Thus, the decision to spend time on passive entertainment activities is related to a lower level of education and this could be reflected in children's behavior.

Especially noteworthy are the results regarding Mediterranean diet adherence, as measured by the KIDMED index, according to parents' education level. They show that nearly half of children and adolescents whose parents had a university education had high adherence to the Mediterranean diet, whereas the percentage was much lower among children whose parents had a low or medium education level. Outcomes that are consistent with ours in this respect have been observed in studies conducted in various countries [66-69]. Yañez et al. have shown that low family educational level is associated with low adherence to the Mediterranean diet in adolescents [70]. It has been described that a low parent education level is associated with little knowledge of nutrition and a low level of awareness about aspects related to nutrition. In these cases, consumers can make mistakes when following nutritional recommendations and healthy diet guidelines [71]. This may explain the low adherence to the Mediterranean diet among children with parents with a lower education level. This leads one to think that in addition to general actions aimed at raising awareness and building adequate food advertising regulations, strategies and interventions aimed at more disadvantaged social classes must also be proposed.

The strengths of this study are that it approaches a topic that has not often been directly studied: the association between time spent on passive entertainment and eating patterns among children and adolescents. Second, it was conducted within the PASOS study on a large, representative sample of the child and adolescent population in Spain and among a wide age range, which provides consistent estimates. Third, the methodology used is rigorous and standardized among all sections, and this study uses validated tools administered by specifically trained personnel. The main limitation of this study is its cross-sectional nature, which makes it impossible to determine the relationship between cause and effect in the associations found. Another limitation could be related to the fact that the information used for screen time and dietary patterns is self-reported, which could have led to less precise estimates. Our study did not examine the influence of parents ${ }^{\prime}$ education level according to their sex, but this is another line of research that could shed light on new data of interest.

\section{Conclusions}

Screen time is associated with a low adherence to the Mediterranean diet in both children (8-11 years) and adolescents (12-16 years). It is also associated with a lower consumption of fruit, vegetables, and legumes, as well as a greater consumption of fast food, sweets, and candy. Screen time is higher among boys than girls in both children and adolescents whose parents have a low education level.

Adopting healthy eating habits goes hand-in-hand with improvements in other lifestyle aspects, such as physical activity and sedentarism. Among children and ado- 
lescents, passive screen time entertainment must be used in a limited, responsible manner in order to avoid excess use. Education is one of the keys to improving dietary and physical activity habits. In addition to general strategies to improve lifestyles and generate healthy environments, specific strategies aimed at social classes with lower education levels must be designed.

Author Contributions: Conceptualization, J.W., N.P.-F. and F.J.B.-L.; methodology, J.W., N.P.-F. and F.J.B.-L.; formal analysis, N.P.-F.; investigation, J.W., N.P.-F., J.C.B.-M., S.F.G., I.L.; A.G.Z.; N.G., S.A., P.E.A., M.G.-V., L.S.-M., N.T., J.A.T., M.S., C.L., C.H., M.O., M.G.-G., J.S.-G., F.J.-Z., E.M.-C., M.S.-S., E.H.-R., S.P., M.d.M.B., O.S.-M., H.S. and F.J.B.-L.; data curation, S.F.G., H.S. and C.H.; writingoriginal draft preparation, J.W., N.P.-F. and F.J.B.-L.; writing-review and editing, all authors; PASOS study design and project administration, S.F.G., H.S. and C.H. All authors defined the strategy to deploy the PASOS study protocol in their assigned schools. All authors have read and agreed to the published version of the manuscript.

Funding: The PASOS study was funded by Fundación PROBITAS and the Gasol Foundation. Additional funds were received from the Barça Foundation, Banco Santander, IFA, Vienna and the Fundación Deporte Jóven. J.A.T. and M.M.B. are funded by the official funding agency for biomedical research of the Spanish government, the Institute of Health Carlos III (ISCIII), which is co-funded by the European Regional Development Fund (CIBEROBN CB12/03/30038).

Institutional Review Board Statement: The PASOS study was conducted according to the guidelines of the Declaration of Helsinki and approved by the Ethics Committee of the Fundació Sant Joan de Déu, Barcelona, Spain.

Informed Consent Statement: A signed informed consent form was obtained from the parent or legal guardian of each participant.

Data Availability Statement: Data sharing not applicable.

Acknowledgments: We thank the staff, pupils, parents, schools and municipalities for their participation, enthusiasm, and support. PASOS has the institutional support of Spain's Ministry of Education and Vocational Training, the Ministry of Health, Consumption and Social Welfare through the Spanish Agency for Food Safety and Nutrition (ASEAN), the High Commission against Child Poverty, the High Sports Council, the General College of Professional Associations of Physical Education and Sports, and the Departments of Education and/or Health and/or Sports of Spain's 17 autonomous regions. The CIBEROBN and the CIBERESP are initiatives from the Institute of Health Carlos III, Madrid, Spain.

Conflicts of Interest: None declared. The funders had no role in the analysis or interpretation of the data in this study.

\section{References}

1. Di Cesare, M.; Sorić, M.; Bovet, P.; Miranda, J.J.; Bhutta, Z.; Stevens, G.A.; Laxmaiah, A.; Kengne, A.P.; Bentham, J. The epidemiological burden of obesity in childhood: A worldwide epidemic requiring urgent action. BMC Med. 2019, 17, 212. [CrossRef]

2. Lobstein, T.; Jackson-Leach, R.; Moodie, M.L.; Hall, K.D.; Gortmaker, S.L.; Swinburn, B.A.; James, W.P.T.; Wang, Y.; McPherson, K. Child and adolescent obesity: Part of a bigger picture. Lancet 2015, 385, 2510-2520. [CrossRef]

3. Park, M.H.; Falconer, C.; Viner, R.M.; Kinra, S. The impact of childhood obesity on morbidity and mortality in adulthood: A systematic review. Obes. Rev. 2012, 13, 985-1000. [CrossRef]

4. Singh, A.S.; Mulder, C.; Twisk, J.W.R.; Van Mechelen, W.; Chinapaw, M.J.M. Tracking of childhood overweight into adulthood: A systematic review of the literature. Obes. Rev. 2008, 9, 474-488. [CrossRef] [PubMed]

5. WHO Childhood Obesity Surveillance Initiative (COSI). Highlights 2015-2017; World Health Organization Regional Office for Europe: Copenhagen, Denmark, 2018; pp. 1-8.

6. Abarca-Gómez, L.; Abdeen, Z.A.; Hamid, Z.A.; Abu-Rmeileh, N.M.; Acosta-Cazares, B.; Acuin, C.; Adams, R.J.; Aekplakorn, W.; Afsana, K.; Aguilar-Salinas, C.A.; et al. Worldwide trends in body-mass index, underweight, overweight, and obesity from 1975 to 2016: A pooled analysis of 2416 population-based measurement studies in 128.9 million children, adolescents, and adults. Lancet 2017, 390. [CrossRef]

7. Garrido-Miguel, M.; Cavero-Redondo, I.; Álvarez-Bueno, C.; Rodríguez-Artalejo, F.; Moreno, L.A.; Ruiz, J.R.; Ahrens, W.; Martínez-Vizcaíno, V. Prevalence and Trends of Overweight and Obesity in European Children from 1999 to 2016: A Systematic Review and Meta-analysis. JAMA Pediatr. 2019, 173. [CrossRef] 
8. Freemark, M. Determinants of Risk for Childhood Obesity. N. Engl. J. Med. 2018, 379, 1371-1372. [CrossRef] [PubMed]

9. Brug, J.; Lien, N.; Klepp, K.I.; van Lenthe, F.J. Exploring overweight, obesity and their behavioural correlates among children and adolescents: Results from the Health-promotion through Obesity Prevention across Europe project. Public Health Nutr. 2010, 13, 1676-1679. [CrossRef]

10. Pate, R.R.; O’Neill, J.R.; Liese, A.D.; Janz, K.F.; Granberg, E.M.; Colabianchi, N.; Harsha, D.W.; Condrasky, M.M.; O’Neil, P.M.; Lau, E.Y.; et al. Factors associated with development of excessive fatness in children and adolescents: A review of prospective studies. Obes. Rev. 2013, 14, 645-658. [CrossRef]

11. Martínez-González, M.A.; Trichopoulou, A. Observational Epidemiology, Lifestyle, and Health: The Paradigm of the Mediterranean Diet. Am. J. Health Promot. 2020, 34, 948-950. [CrossRef]

12. Serra-Majem, L.; Ribas, L.; Ngo, J.; Ortega, R.M.; García, A.; Pérez-Rodrigo, C.; Aranceta, J. Food, youth and the Mediterranean diet in Spain. Development of KIDMED, Mediterranean Diet Quality Index in children and adolescents. Public Health Nutr. 2004, 7, 931-935. [CrossRef]

13. Tapia Serrano, M.A.; Vaquero-Solís, M.; López-Gajardo, M.A.; Sánchez-Miguel, P.A. Adherencia a la dieta mediterránea e importancia de la actividad física y el tiempo de pantalla en los adolescentes extremeños de enseñanza secundaria. Nutr. Hosp. 2020, 31. [CrossRef]

14. Bawaked, R.A.; Gomez, S.F.; Homs, C.; Casas Esteve, R.; Cardenas, G.; Fíto, M.; Schröder, H. Association of eating behaviors, lifestyle, and maternal education with adherence to the Mediterranean diet in Spanish children. Appetite 2018, 130, 279-285. [CrossRef] [PubMed]

15. Arriscado, D.; Muros, J.J.; Zabala, M.; Dalmau, J.M. Factors associated with low adherence to a Mediterranean diet in healthy children in northern Spain. Appetite 2014, 80, 28-34. [CrossRef] [PubMed]

16. Halford, J.C.; Boyland, E.J.; Hughes, G.M.; Stacey, L.; McKean, S.; Dovey, T.M. Beyond-brand effect of television food advertisements on food choice in children: The effects of weight status. Public Health Nutr. 2008, 11, 897-904. [CrossRef]

17. Matheson, D.M.; Killen, J.D.; Wang, Y.; Varady, A.; Robinson, T.N. Children's food consumption during television viewing. Am. J. Clin. Nutr. 2004, 79, 1088-1094. [CrossRef] [PubMed]

18. Bellissimo, N.; Pencharz, P.B.; Thomas, S.G.; Anderson, G.H. Effect of television viewing at mealtime on food intake after a glucose preload in boys. Pediatr. Res. 2007, 61, 745-749. [CrossRef]

19. Burt, J.; Dube, L.; Thibault, L.; Gruber, R. Sleep and eating in childhood: A potential behavioral mechanism underlying the relationship between poor sleep and obesity. Sleep Med. 2014, 15, 71-75. [CrossRef] [PubMed]

20. Tajeu, G.S.; Sen, B. New Pathways From Short Sleep to Obesity? Associations Between Short Sleep and "Secondary" Eating and Drinking Behavior. Am. J. Health Promot. 2015, 31, 181-188. [CrossRef]

21. Dennison, B.A.; Erb, T.A.; Jenkins, P.L. Television viewing and television in bedroom associated with overweight risk among low-income preschool children. Pediatrics 2002, 109, 1028-1035. [CrossRef]

22. Pérez-Farinós, N.; Villar-Villalba, C.; López Sobaler, A.M.; Dal Re Saavedra, M.Á.; Aparicio, A.; Santos Sanz, S.; Robledo de Dios, T.; Castrodeza-Sanz, J.J.; Ortega Anta, R.M. The relationship between hours of sleep, screen time and frequency of food and drink consumption in Spain in the 2011 and 2013 ALADINO: A cross-sectional study. BMC Public Health 2017, 17, 33. [CrossRef] [PubMed]

23. Kenney, E.L.; Gortmaker, S.L. United States Adolescents' Television, Computer, Videogame, Smartphone, and Tablet Use: Associations with Sugary Drinks, Sleep, Physical Activity, and Obesity. J. Pediatr. 2016, 182, 144-149. [CrossRef] [PubMed]

24. Erola, J.; Jalonen, S.; Lehti, H. Parental education, class and income over early life course and children's achievement. Res. Soc. Stratif. Mobil. 2016, 44, 33-43. [CrossRef]

25. Pons, M.; Bennasar-Veny, M.; Yañez, A.M. Maternal Education Level and Excessive Recreational Screen Time in Children: A Mediation Analysis. Int. J. Environ. Res. Public Health 2020, 17, 8930. [CrossRef]

26. Lutz, W.; Kebede, E. Education and Health: Redrawing the Preston Curve. Popul. Dev. Rev. 2018, 44, 343-361. [CrossRef] [PubMed]

27. Pérez-Rodrigo, C.; Gil, Á.; González-Gross, M.; Ortega, R.M.; Serra-Majem, L.; Varela-Moreiras, G.; Aranceta-Bartrina, J. Clustering of dietary patterns, lifestyles, and overweight among Spanish children and adolescents in the ANIBES study. Nutrients 2015, 8, 11. [CrossRef]

28. Grao-Cruces, A.; Nuviala, A.; Fernández-Martínez, A.; Porcel-Gálvez, A.M.; Moral-García, J.E.; Martínez-López, E.J. Adherencia a la dieta mediterránea en adolescentes rurales y urbanos del sur de España, satisfacción con la vida, antropometría y actividades físicas y sedentarias. Nutr. Hosp. 2013, 28, 1129-1135. [CrossRef]

29. Gómez, S.F.; Homs, C.; Wärnberg, J.; Medrano, M.; Gross, M.G.; Gusi, N.; Aznar, S.; Cascales, E.M.; Tur, J.A.; Segú, M.; et al. Study protocol of a population-based cohort investigating Physical Activity, Sedentarism, lifestyles and Obesity in Spanish youth: The PASOS study. BMJ Open 2020, 10, e036210. [CrossRef]

30. Mariscal-Arcas, M.; Rivas, A.; Velasco, J.; Ortega, M.; Caballero, A.M.; Olea-Serrano, F. Evaluation of the Mediterranean Diet Quality Index (KIDMED) in children and adolescents in Southern Spain. Public Health Nutr. 2009, 12, 1408-1412. [CrossRef] [PubMed]

31. García Cabrera, S.; Herrera Fernández, N.; Rodríguez Hernández, C.; Nissensohn, M. KIDMED test; prevalence of low adherence to the Mediterranean Diet in children and young; a systematic review. Nutr. Hosp. 2015, 32, 2390-2399. [CrossRef] 
32. Rey-López, J.P.; Ruiz, J.R.; Ortega, F.B.; Verloigne, M.; Vicente-Rodriguez, G.; Gracia-Marco, L.; Gottrand, F.; Molnar, D.; Widhalm, K.; Zaccaria, M.; et al. Reliability and validity of a screen time-based sedentary behaviour questionnaire for adolescents: The HELENA study. Eur. J. Public Health 2012, 22, 373-377. [CrossRef]

33. Barja-Fernández, S.; Pino Juste, M.; Portela Pino, I.; Leis Trabazo, R. Evaluación de los hábitos de alimentación y actividad física en escolares gallegos. Nutr. Hosp. 2020, 37, 93-100. [CrossRef]

34. WHO-World Health Organization Weighing and Measuring a Child. Training Course and Other Tools. 2019. Available online: https:/ / www.who.int/childgrowth/training/en/ (accessed on 11 February 2021).

35. De Onis, M.; Onyango, A.W.; Borghi, E.; Siyam, A.; Nishida, C.; Siekmann, J. Development of a WHO growth reference for school-aged children and adolescents. Bull. World Health Organ. 2007, 85, 660-667. [CrossRef] [PubMed]

36. De Jong, E.; Visscher, T.L.S.; HiraSing, R.A.; Heymans, M.W.; Seidell, J.C.; Renders, C.M. Association between TV viewing, computer use and overweight, determinants and competing activities of screen time in 4- to 13-year-old children. Int. J. Obes. 2013, 37, 47-53. [CrossRef]

37. Shang, L.; Wang, J.; O'Loughlin, J.; Tremblay, A.; Mathieu, M.-È.; Henderson, M.; Gray-Donald, K. Screen time is associated with dietary intake in overweight Canadian children. Prev. Med. Rep. 2015, 2, 265-269. [CrossRef] [PubMed]

38. Zhang, G.; Wu, L.; Zhou, L.; Lu, W.; Mao, C. Television watching and risk of childhood obesity: A meta-analysis. Eur. J. Public Health 2016, 26, 13-18. [CrossRef]

39. Twarog, J.P.; Politis, M.D.; Woods, E.L.; Boles, M.K.; Daniel, L.M. Daily television viewing time and associated risk of obesity among U.S. preschool aged children: An analysis of NHANES 2009-2012. Obes. Res. Clin. Pract. 2015, 9, 636-638. [CrossRef] [PubMed]

40. Lissner, L.; Lanfer, A.; Gwozdz, W.; Olafsdottir, S.; Eiben, G.; Moreno, L.A.; Santaliestra-Pasías, A.M.; Kovács, E.; Barba, G.; Loit, H.M.; et al. Television habits in relation to overweight, diet and taste preferences in European children: The IDEFICS study. Eur. J. Epidemiol. 2012, 27, 705-715. [CrossRef]

41. Rosiek, A.; Maciejewska, N.F.; Leksowski, K.; Rosiek-Kryszewska, A.; Leksowski, Ł. Effect of Television on Obesity and Excess of Weight and Consequences of Health. Int. J. Environ. Res. Public Health 2015, 12, 9408-9426. [CrossRef]

42. Vandewater, E.A.; Park, S.E.; Hébert, E.T.; Cummings, H.M. Time with friends and physical activity as mechanisms linking obesity and television viewing among youth. Int. J. Behav. Nutr. Phys. Act. 2015, 12, S6. [CrossRef]

43. Smith, L.; Fisher, A.; Hamer, M. Television viewing time and risk of incident obesity and central obesity: The English longitudinal study of ageing. BMC Obes. 2015, 2, 12. [CrossRef]

44. Katzmarzyk, P.T.; Barreira, T.V.; Broyles, S.T.; Champagne, C.M.; Chaput, J.-P.; Fogelholm, M.; Hu, G.; Johnson, W.D.; Kuriyan, R.; Kurpad, A.; et al. Relationship between lifestyle behaviors and obesity in children ages 9-11: Results from a 12-country study. Obesity 2015, 23, 1696-1702. [CrossRef]

45. Whiting, S.; Buoncristiano, M.; Gelius, P.; Abu-Omar, K.; Pattison, M.; Hyska, J.; Duleva, V.; Music-Milanovic, S.; Zamrazilova, H.; Hejgaard, T.; et al. Physical Activity, Screen Time, and Sleep Duration of Children Aged 6-9 Years in 25 Countries: An Analysis within the WHO European Childhood Obesity Surveillance Initiative (COSI) 2015-2017. Obes. Facts 2020, 125009. [CrossRef]

46. Börnhorst, C.; Wijnhoven, T.M.; Kunešová, M.; Yngve, A.; Rito, A.I.; Lissner, L.; Duleva, V.; Petrauskiene, A.; Breda, J. WHO European Childhood Obesity Surveillance Initiative: Associations between sleep duration, screen time and food consumption frequencies. BMC Public Health 2015, 15. [CrossRef]

47. Blaine, R.E.; Fisher, J.O.; Blake, C.E.; Orloski, A.; Younginer, N.; Bruton, Y.; Ganter, C.; Rimm, E.B.; Geller, A.C.; Davison, K.K. Conditioned to eat while watching television? Low-income caregivers' perspectives on the role of snacking and television viewing among pre-schoolers. Public Health Nutr. 2016, 19, 1598-1605. [CrossRef] [PubMed]

48. Borghese, M.M.; Tremblay, M.S.; Leduc, G.; Boyer, C.; Belanger, P.; LeBlanc, A.G.; Francis, C.; Chaput, J.P. Television viewing and food intake during television viewing in normal-weight, overweight and obese 9- to 11-year-old Canadian children: A cross-sectional analysis. J. Nutr. Sci. 2015, 4, e8. [CrossRef] [PubMed]

49. Falbe, J.; Willett, W.C.; Rosner, B.; Gortmaker, S.L.; Sonneville, K.R.; Field, A.E. Longitudinal relations of television, electronic games, and digital versatile discs with changes in diet in adolescents. Am. J. Clin. Nutr. 2014, 100, 1173-1181. [CrossRef]

50. Pearson, N.; Biddle, S.J.H. Sedentary behavior and dietary intake in children, adolescents, and adults: A systematic review. Am. J. Prev. Med. 2011, 41, 178-188. [CrossRef]

51. Mielgo-Ayuso, J.; Aparicio-Ugarriza, R.; Castillo, A.; Ruiz, E.; Avila, J.M.; Aranceta-Bartrina, J.; Gil, A.; Ortega, R.M.; Serra-Majem, L.; Varela-Moreiras, G.; et al. Sedentary behavior among Spanish children and adolescents: Findings from the ANIBES study. BMC Public Health 2017, 17, 94. [CrossRef]

52. Guran, T.; Bereket, A. International epidemic of childhood obesity and television viewing. Minerva Pediatr. 2011, 63, 483-490. [PubMed]

53. Kelly, B.; Freeman, B.; King, L.; Chapman, K.; Baur, L.; Gill, T. Television advertising, not viewing, is associated with negative dietary patterns in children. Pediatr. Obes. 2016, 11, 158-160. [CrossRef]

54. Ustjanauskas, A.E.; Harris, J.L.; Schwartz, M.B. Food and beverage advertising on children's web sites. Pediatr. Obes. 2014, 9 , 362-372. [CrossRef]

55. López-Gil, J.F.; Reis Gaya, A.; dos Santos Duarte Junior, M.A.; Yuste Lucas, J.L. Meeting international screen-time guidelines is associated with healthy dietary patterns in Spanish schoolchildren. Nutr. Hosp. 2020, 37. [CrossRef] 
56. Rasmussen, M.; Krølner, R.; Klepp, K.-I.; Lytle, L.; Brug, J.; Bere, E.; Due, P. Determinants of fruit and vegetable consumption among children and adolescents: A review of the literature. Part I: Quantitative studies. Int. J. Behav. Nutr. Phys. Act. 2006, 3, 22. [CrossRef] [PubMed]

57. Giese, H.; König, L.M.; Tăut, D.; Ollila, H.; Băban, A.; Absetz, P.; Schupp, H.; Renner, B. Exploring the association between television advertising of healthy and unhealthy foods, self-control, and food intake in three European countries. Appl. Psychol. Health Well Being 2015, 7, 41-62. [CrossRef]

58. Benaich, S.; Mehdad, S.; Andaloussi, Z.; Boutayeb, S.; Alamy, M.; Aguenaou, H.; Taghzouti, K. Weight status, dietary habits, physical activity, screen time and sleep duration among university students. Nutr. Health 2020, 1-10. [CrossRef] [PubMed]

59. Vizcaino, M.; Buman, M.; Desroches, T.; Wharton, C. From TVs to tablets: The relation between device-specific screen time and health-related behaviors and characteristics. BMC Public Health 2020, 20, 1295. [CrossRef] [PubMed]

60. Myszkowska-Ryciak, J.; Harton, A.; Lange, E.; Laskowski, W.; Wawrzyniak, A.; Hamulka, J.; Gajewska, D. Reduced screen time is associated with healthy dietary behaviors but not body weight status among Polish adolescents. Report from the wise nutrition-healthy generation project. Nutrients 2020, 12, 1323. [CrossRef] [PubMed]

61. Abdel Magid, H.S.; Milliren, C.E.; Gabriel, K.P.; Nagata, J. Disentangling individual, school, and neighborhood effects on screen time among adolescents and young adults in the United States. Prev. Med. 2020, 142, 106357. [CrossRef]

62. Farrell, L.; Hollingsworth, B.; Propper, C.; Shields, M.A. The socioeconomic gradient in physical inactivity: Evidence from one million adults in England. Soc. Sci. Med. 2014, 123, 55-63. [CrossRef]

63. Ma, Y.; Nolan, A.; Smith, J.P. The value of education to health: Evidence from Ireland. Econ. Hum. Biol. 2018, 31, 14-25. [CrossRef] [PubMed]

64. Cawley, J. An economic framework for understanding physical activity and eating behaviors. Am. J. Prev. Med. 2004, 27, 117-125. [CrossRef]

65. Huikari, S.; Junttila, H.; Ala-Mursula, L.; Jämsä, T.; Korpelainen, R.; Miettunen, J.; Svento, R.; Korhonen, M. Leisure-time physical activity is associated with socio-economic status beyond income-Cross-sectional survey of the Northern Finland Birth Cohort 1966 study. Econ. Hum. Biol. 2021, 41, 100969. [CrossRef]

66. Kosti, R.I.; Kanellopoulou, A.; Fragkedaki, E.; Notara, V.; Giannakopoulou, S.-P.; Antonogeorgos, G.; Rojas-Gil, A.P.; Kornilaki, E.N.; Lagiou, A.; Panagiotakos, D.B. The Influence of Adherence to the Mediterranean Diet among Children and Their Parents in Relation to Childhood Overweight/Obesity: A Cross-Sectional Study in Greece. Child. Obes. 2020, 16, 571-578. [CrossRef] [PubMed]

67. La Fauci, V.; Alessi, V.; Assefa, D.Z.; Lo Giudice, D.; Calimeri, S.; Ceccio, C.; Antonuccio, G.M.; Genovese, C.; Squeri, R. Mediterranean diet: Knowledge and adherence in Italian young people. Clin. Ter. 2020, 171, e437-e443. [CrossRef] [PubMed]

68. Plaza-Díaz, J.; Molina-Montes, E.; Soto-Méndez, M.J.; Madrigal, C.; Hernández-Ruiz, Á.; Valero, T.; Villoslada, F.L.; Leis, R.; de Victoria, E.M.; Moreno, J.M.; et al. Clustering of dietary patterns and lifestyles among spanish children in the EsNuPi study. Nutrients 2020, 12, 2536. [CrossRef]

69. Costarelli, V.; Michou, M.; Panagiotakos, D.B.; Lionis, C. Adherence to the Mediterranean diet and weight status in children: The role of parental feeding practices. Int. J. Food Sci. Nutr. 2020, 72, 112-122. [CrossRef] [PubMed]

70. Yañez, A.M.; Bennasar-Veny, M.; Leiva, A.; García-Toro, M. Implications of personality and parental education on healthy lifestyles among adolescents. Sci. Rep. 2020, 10, 7911. [CrossRef]

71. Cavaliere, A.; De Marchi, E.; Banterle, A. Exploring the adherence to the mediterranean diet and its relationship with individual lifestyle: The role of healthy behaviors, pro-environmental behaviors, income, and education. Nutrients 2018, 10, 141. [CrossRef] [PubMed] 